\title{
CITTASLOW: VIDA LENTA E SUSTENTABILIDADE NAS CIDADES DO BEM VIVER
}

\author{
Rubens Moreira Rodrigues de Carvalho ${ }^{1}$
}

\begin{abstract}
RESUMO
O Cittaslow (Movimento das Cidades Lentas) é uma iniciativa que associa a "lentidão" ao bem-estar e ao desenvolvimento urbano sustentável. Baseado na filosofia do Slow Food (a antítese do fast food), o movimento dá valor ao típico, preservando a diversidade cultural e ambiental dos lugares tradicionais. Nesse trabalho, que é parte de uma tese de doutorado em andamento, apresentamos as relações da "vida lenta", isto é, dos modos de vida protegidos pelo Cittaslow, com a ecologia e a sustentabilidade. Para isso, iremos abordar o fenômeno da "cidade lenta" (e da "rede internacional das cidades do bem viver") em sua essência, discorrendo sobre suas principais questões. Nossa intenção é difundir o tema no Brasil, enriquecendo o seu arcabouço teórico-conceitual, e enfatizar as contribuições do movimento para a conservação da identidade cultural e para a formação de cidades "lentas" e sustentáveis.
\end{abstract}

PALAVRAS-CHAVE: Cittaslow (Cidade Lenta). Sustentabilidade urbana. Identidade cultural.

\section{CITTASLOW: SLOW LIFE AND SUSTAINABILITY IN THE CITIES WHERE LIVING IS GOOD}

\begin{abstract}
The Cittaslow (the Slow Cities Movement) is an initiative that combines "slowness" with sustainable urban development. Based on the Slow Food philosophy (the antithesis of fast food), the movement seeks the real development of the communities, while preserving its unique character and the cultural and environmental diversity of traditional places. This article presents the "slow life" (the traditional ways of life) as a concept linked to ecology and sustainability. For this, we address the issue of slow cities and their "international network of cities where life is good". Our intention is to spread the Cittaslow concept in Brazil, highlighting their contributions to the conservation of cultural identity and formation of "slow" and sustainable cities.
\end{abstract}

KEYWORDS: Cittaslow (Slow City). Urban sustainability. Cultural identity.

\footnotetext{
${ }^{1}$ Mestre em Arquitetura e Urbanismo pela Universidade Federal Fluminense (PPGAU/UFF), Aluno de Doutorado do Programa de Pós-Graduação em Arquitetura e Urbanismo pela Universidade Federal Fluminense (PPGAU/UFF). E-mail: rubens.mrc@hotmail.com
} 


\title{
CITTASLOW: VIDA LENTA Y SOSTENIBILIDAD EN LAS CIUDADES DEL BUEN VIVIR
}

\begin{abstract}
RESUMEN
El Cittaslow (el Movimiento Ciudad Lenta) es una iniciativa que combina la "lentitud" con el desarrollo urbano sostenible. Basado en la filosofía Slow Food (la antítesis del fast food), el movimiento busca el verdadero desarrollo de las comunidades, preservando, al mismo tiempo, su carácter único y la diversidad cultural y medioambiental de los lugares tradicionales. Este artículo presenta la "vida lenta" (las formas de vida tradicionales) como un concepto ligado a la ecología y la sostenibilidad. Para ello, se aborda el tema de la ciudad lenta y de la "red internacional de ciudades del buen vivir". Nuestra intención es difundir el concepto Cittaslow en Brasil, destacando su contribución a la conservación de la identidad cultural y la formación de las ciudades "lentas" y sostenibles.
\end{abstract}

PALABRAS-CLAVE: Cittaslow (Ciudad Lenta). Sostenibilidad urbana. Identidad cultural.

\section{INTRODUÇÃO}

A utopia está lá no horizonte. Me aproximo dois passos, ela se afasta dois passos. Caminho dez passos e o horizonte corre dez passos. Por mais que eu caminhe, jamais alcançarei. Para que serve a utopia? Serve para isso: para que eu não deixe de caminhar (GALEANO, 1994, p.310).

Deparamo-nos com uma crise ambiental sem precedentes na história da humanidade, com impactos diretos sobre a vida das pessoas e a vida no planeta. A questão ambiental, em diversos aspectos, pode ser associada ao fenômeno urbano, isto é, também está relacionada aos modos de vida e à organização espacial da sociedade contemporânea - que, cada vez mais, assume o urbano como principal habitat. O uso desmedido e irresponsável dos recursos naturais, com a finalidade de subsidiar uma relação ideal de produção e consumo, está nos levando a um evidente estado de insustentabilidade. A poluição, a crescente imprevisibilidade do clima, a degradação de importantes ecossistemas, a extinção de espécies animais e vegetais e as diversas crises envolvendo a água, a energia e os alimentos, são exemplos das alterações ambientais que, de algum modo, podem ser atribuídas às ações humanas ou à sua interferência no equilíbrio natural do planeta.

Nesse contexto, a saída mais adequada pode ser a de unir sustentabilidade ao desenvolvimento. Precisamos, com urgência, de abordagens mais ecológicas e 
humanistas, de métodos práticos e imaginativos que nos permitam lidar, de modo simultâneo, com os problemas do presente e do futuro. Em todo o planeta, eclodem manifestações sociais questionando as atuais condições de vida nas cidades - não apenas nas cidades, mas, sobretudo, nelas. São essas manifestações, por sua vez, que nos levam à emergência de movimentos em favor do bem-estar social, em favor da formação de ambiências que facilitem o viver com qualidade.

Dentre essas ações, destacam-se as iniciativas do Slow Food e do Cittaslow. Movimentos que, a seu modo, buscam formas de valorizar as pessoas e o território e de proteger a biodiversidade e a diversidade cultural, para, desse modo, promover o bem-estar e a qualidade de vida. São ações que participam da corrente "slow", isto é, do slow movement ${ }^{2}$, e que se anunciam como verdadeiras barreiras (ou barricadas culturais) contra o consumismo e contra os demais efeitos negativos da produção e do consumo no ambiente e na vida das pessoas.

Nesse trabalho, temos como objetivo avaliar as contribuições do Slow Food e do Cittaslow para a proposta do desenvolvimento urbano sustentável. Nossa ênfase, no entanto, recai sobre o Cittaslow, sobre a proposta da "cidade lenta" e os "modos de vida lentos". Para dar maior clareza à análise, optamos por dividir o trabalho em três partes: na primeira, abordamos o contexto que levou ao surgimento do Slow Food e do Cittaslow; na segunda, apresentamos aspectos de suas propostas; e, na terceira, tratamos das correlações entre a cidade lenta e a sustentabilidade da cidade.

\section{A GLOBALIZAÇÃO, O MUNDO RÁPIDO E O SENTIDO DE LUGAR.}

O mundo rápido é muito mais um produto da expansão do capitalismo em escala global. No sistema econômico global, o tempo custa dinheiro, e o resultado inevitável é a aceleração constante do ritmo de vida (KNOX, 2005, p.3, tradução própria).

O espaço é mais abstrato que o lugar (TUAN, 1983, p.06). O "espaço em si" pode até ser algo primordialmente dado, mas sua organização e sentido são

\footnotetext{
${ }^{2}$ O Slow Movement congrega uma série de iniciativas "slow" (slow food, slow cities, slow travel e etc.) e fomenta uma mudança cultural ligada ao ritmo de vida das pessoas, isto é, à possibilidade de uma vida plena e desacelerada, onde cada indivíduo tenha controle sobre suas ações cotidianas.
} 
produtos das ações, transformações e experiências sociais (SOJA, 1993, p.101). As pessoas moram, trabalham e se relacionam em lugares, moldando e adaptando esses lugares à sua lógica, aos seus valores e necessidades. O comportamento social, por sua vez, também é influenciado pelas características do lugar, o que constitui uma relação de interação dialética, entre ambiente e sociedade, que é descrita por Soja (1993) como a dialética socioespacial ${ }^{3}$.

Nesse contexto de múltiplas interferências, onde as pessoas constantemente modificam e reformulam os lugares, e os lugares lidam igualmente com as mudanças e, ao mesmo tempo, influenciam as pessoas (KNOX, 2005, p.03), fenômenos como a globalização e o "mundo rápido" (fast world) - veiculados como aspectos inerentes ao "progresso" de nossa civilização - produzem impactos que afetam tanto os modos de vida, isto é, os hábitos e costumes da sociedade, quanto os lugares, nas dimensões física e cultural que os compõem. Não por acaso, após a emergência da globalização e do mundo rápido, pessoas e lugares passaram a se confrontar com mudanças em escalas e taxas extraordinárias, sem precedentes na história humana.

A globalização, isto é, o processo de integração política, cultural e econômica dos povos do planeta, ganhou força a partir dos avanços científicos e tecnológicos e da evolução dos meios de comunicação e de transportes, decorridos, principalmente, ao longo da segunda metade do século XX. Com a ruína do socialismo e a ascensão do capitalismo como sistema hegemônico global, a globalização passou a ser vista também como um processo "irreversível". Mas a integração cultural e econômica dos povos, no entanto, resulta em uma "sociedade em rede", que é altamente dominada por fluxos de capital, ideias e pessoas (CASTELLS, 1996, In: KNOX, 2005). Conduz, portanto, à desterritorialização, ou seja, à dissolução de valores e de culturas locais, levando à corrosão da origem do sujeito e à perda do sentido de lugar e do sentido de comunidade - o que leva o sujeito a não reconhecer mais o seu lugar no mundo.

\footnotetext{
${ }^{3}$ A dialética reconhece um processo constante de oposição e unidade entre o espaço e a sociedade. Um como constituinte do outro, mesmo que sejam coisas ontologicamente diferentes (SOJA, 1993).
} 
Sentido de lugar e sentido de comunidade são aspectos ligados à afirmação da identidade cultural e estão associados ao vínculo do homem com a cultura e com o território que o significa. Norberg-Schulz (1980) descreve o sentido de lugar como o "caráter do lugar" ou, em outros termos, como o gênius loci ${ }^{4}$. Representa, segundo o autor, o conjunto de características socioculturais que diferenciam o lugar, isto é, o "gênio" ou o "espírito" do lugar que é habitado ou frequentado pelo homem. Com o avanço da globalização, o sentido de lugar passou a ser constantemente ameaçado. Hoje, "tudo" é mundial ou está em trânsito e isso faz com que as pessoas se sintam, quase sempre, "fora do lugar" ou "estrangeiras" em seu próprio território.

As relações de hoje mudam muito rápido e essa "rapidez" altera o modo como as pessoas e os lugares reagem às transformações, afetando o ambiente e a vida das pessoas. A "rapidez", portanto, está ligada ao mundo rápido e à globalização, ou seja, é o agente de um mundo em constante alteração. Para Knox (2005), esse mundo é "um mundo de paisagens inquietas", onde os lugares mudam o tempo todo e, quanto mais mudam, mais perecidos ficam. A velocidade das mudanças serve também para facilitar a dominação econômica e cultural, alterando produtos, serviços, mercados, consumidores e, por consequência, o resultado de tudo isso. A evolução constante e acelerada também influencia os saberes, o conhecimento, as formas de comunicação, os métodos de trabalho e os modos de vida da sociedade.

É o mundo rápido que nos leva à "vida rápida" (fast life), isto é, à vida que é ditada pelo ritmo da produção e do consumo. A vida rápida é um produto da cultura ocidental, da cultura consumista, e adota como regra a máxima produtividade (time is money!). Representa um estilo de vida que hoje está presente em grande parte das cidades (capitalistas) do planeta. Ao privilegiar os anseios econômicos, em detrimento das necessidades humanas, a vida rápida leva o homem a se desligar ainda mais da natureza e de seu próprio ritmo biológico. Para a vida rápida a "quantidade" é mais importante do que a "qualidade", e isso tem se refletido na

${ }^{4}$ O gênius loci é um conceito romano. Norberg-Schulz (1980, p.18) afirma que, de acordo com antigas crenças romanas, cada ser independente possui um gênio, ou seja, uma espécie de espírito guardião que dá vida e personalidade à pessoas e lugares. O gênio é o que uma coisa "é" ou o que "quer ser". 


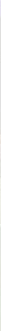

formação de cidades cada vez maiores, mais densas e, ao mesmo tempo, individualizadas.

Schlosser (2001) aponta o fast food como o maior símbolo da vida rápida. Em seu livro, Fast Food Nation, o autor debate sobre a verdadeira conjuntura econômica, política e social que sustenta essa indústria. Faz um alerta, indicando que por trás dos fast foods existem diversos danos socioambientais, como a superexploração da mão de obra, a desmedida exploração de recursos não renováveis e, dentre outros tantos, a constante alienação da técnica ${ }^{5}$, do saber-fazer local e tradicional. Heidegger (1988) complementa afirmando que o progresso, o racionalismo e os valores de massa criam apenas lugares comuns, sem distinção e sem identidade própria, e isso se reflete na qualidade da ambiência e na qualidade de vida das pessoas. A vida rápida, portanto, está subvertendo a autenticidade das pessoas e dos lugares, corroendo a pluralidade cultural e subtraindo, aos poucos, a qualidade dos momentos diariamente vividos.

\section{SLOW FOODE O PRINCÍPIO DA LENTIDÃO.}

Há um vínculo secreto entre a lentidão e a memória, entre a velocidade e o esquecimento. (...) o grau de lentidão é diretamente proporcional a intensidade da memória; o grau de velocidade é diretamente proporcional à intensidade do esquecimento (KUNDERA, 2011, p.30-31).

O Slow Food (Movimento da Comida Lenta) apresenta-se como uma crítica e como uma resposta aos males da globalização e do mundo rápido. É uma iniciativa que se dedica a proteger a cultura e a identidade gastronômica local, combatendo a "padronização do gosto" e o domínio econômico e cultural das redes de fast food. Seu objetivo é impedir a implacável hegemonia das chamadas empresas globais, como o McDonalds, a Wal-Mart, o Starbucks, a Tesco e outros tantos ícones do consumismo (MAYER; KNOX, 2010, p.1552).

O Slow Food nasceu em 1986, na Itália, em função de um protesto, liderado por Carlo Petrini (jornalista e crítico gastronômico da região de Piemonte), contra a

\footnotetext{
${ }^{5}$ Heidegger (1988) ressalta que a técnica, quando usada para esclarecer e revelar, e não apenas para produzir e fabricar, é importante para a preservação da memória e da identidade cultural, contribuindo para a autenticidade das culturas e dos lugares.
} 
abertura de uma lanchonete McDonalds ao lado da Piazza di Spagna, famoso bem cultural do centro histórico de Roma. Em 1989, o protesto oficializou-se na forma de um manifesto contra a industrialização, a economia global, a padronização cultural e o consumo irresponsável e desenfreado. Para o Slow Food, a globalização representa uma potencial ameaça à agricultura tradicional, ao consumo de alimentos saudáveis, à sociabilidade e aos demais valores das culturas locais. Em seus discursos, Petrini busca valorizar a produção local e o prazer de "sentar-se à mesa", isto é, de desfrutar calmamente de uma boa refeição, protegendo o "direito de provar" (right to taste) e as principais características do ritmo de vida "lento" (MAYER; KNOX, 2006, p.326).

A base da filosofia do Slow Food é a "lentidão", ou seja, a diminuição do ritmo das atividades humanas. Para isso, convida as pessoas a ter mais interesse pelo ciclo produtivo do alimento e a compreender os verdadeiros impactos socioambientais da produção, do transporte e do consumo de alimentos na cidade, chamando a atenção para os sabores, aromas e valores da cozinha regional. Para o Slow Food, optar por "produtos da terra" é uma forma de experimentar a energia do território, ajudando a preservar (ou recuperar) saberes tradicionais e valores culturas locais.

Enquanto as indústrias "despejam" alimentos homogêneos e baratos, as mãos de pequenos produtores oferecem produtos únicos, diferentes, artesanais, que não podem ser repetidos nem multiplicados ao infinito porque são feitos de gestos precisos, de saberes antigos e tradições locais, truques secretos passados ao pé do ouvido (SLOW FOOD, 2013).

Mayer e Knox (2010) citam o caso que envolve a produção de vinho na região de Cinque Terre (um acidentado trecho de terra na costa da Riviera Ligure, na Itália), como um bom exemplo de conexão, entre ambiente e economia local, obtido a partir de ações do Slow Food. Caracterizada por um relevo íngreme e montanhoso próximo ao mar, a região, que em 1997 recebeu da Unesco o título de Patrimônio Cultural da Humanidade, teve sua produção de vinho quase extinta por conta da hostilidade do terreno e da estagnação da economia local. O que fez boa parte da população mais jovem migrar para os grandes centros, em busca de oportunidades e empregos. Para reverter esse cenário, o Slow Food incentivou a proteção das 
vinhas, situando-as como bem cultural, e enfatizou a qualidade do vinho produzido no local. Apoiou cursos para qualificar as técnicas, a mão de obra e aprimorar o peculiar sistema de produção em terraços com grande inclinação. A qualidade do produto ajudou a elevar seu preço e a renovar a economia local, fazendo com que as gerações mais novas voltassem a se interessar pela indústria do vinho. Isso ajudou a fortalecer os vínculos locais, preservando as tradições, as técnicas e a paisagem da região, recuperando a economia e a vida das comunidades envolvidas.

Hoje, o Slow Food é uma organização internacional, que possui mais de 100 mil membros e marca presença em 150 países. Atua no Brasil de modo oficial desde 2004, em campanhas para a preservação e para a valorização de produtos e técnicas produtivas tradicionais, ligadas às culturas regionais. Entre as ações, estão: a defesa da produção de queijos artesanais e de leite cru; o slow fish (a pesca artesanal); as campanhas contra os alimentos transgênicos; e contra a grilagem de terras (SLOW FOOD, 2013). A cada ano, o Slow Food aumenta sua importância e sua abrangência e, não por acaso, tornou-se a base conceitual da proposta da cidade lenta.

\section{CITTASLOW: A CIDADE DA VIDA LENTA.}

É inútil forçar os ritmos da vida. A arte de viver consiste em aprender a dar o devido tempo às coisas (Carlo Petrini, 2007, In: SLOW FOOD, 2013).

O Cittaslow (Movimento das Cidades Lentas) inspira-se na proposta do Slow Food e sua intenção é levar a "lentidão" para a escala das cidades, dos problemas do meio urbano, incentivando a desaceleração das práticas cotidianas, da produção e do consumo. Mayer e Knox (2006) o descrevem como um movimento dedicado a elevar a qualidade de vida, como uma proposta de desenvolvimento urbano sustentável, que conserva o caráter distintivo local e valoriza o território, o indivíduo, a biodiversidade e a diversidade cultural. Manifesta-se, tal como o Slow Food, contra o consumismo, a globalização e os hábitos sociais que situam o "ter" acima do "ser".

Surgiu oficialmente em 1999, quando Paolo Saturnini, então prefeito de Greve in Chianti (pequena comunidade da Toscana, na Itália), organizou um 
encontro com prefeitos de outros três municípios de porte semelhante, com o objetivo de definir os atributos de uma cidade "lenta" (KNOX, 2005, p.06). Na ocasião, os quatro prefeitos ${ }^{6}$ assinaram um acordo, no qual se comprometiam a trabalhar para proteger o típico, a paisagem, as tradições e as singularidades das pequenas comunidades urbano-rurais da Itália. Sua missão, portanto, é a de conciliar o desenvolvimento econômico dessas comunidades, com a conservação e a formação de ambientes físicos mais calmos e menos poluídos, tentando levar aspectos da sustentabilidade e da ecogastronomia ${ }^{7}$ para a vida cotidiana (MAYER; KNOX, 2006, p.327).

O Cittaslow nasceu na Itália (assim como o Slow Food), mas seus ideais logo atingiram outros países e outras culturas. Hoje, o movimento é representado por uma organização não governamental (Cittaslow International), que se autodenomina como a "rede internacional das cidades do bem viver". Sua principal finalidade, enquanto organização, é difundir o conceito da cidade lenta, da "cidade do bem viver", fazendo com os municípios invistam mais em qualidade de vida. Conforme a última listagem divulgada, em abril de 2015, a rede Cittaslow envolve hoje 195 cidades, em 30 países diferentes (CITTASLOW, 2015). A maioria das cidades lentas encontra-se na Europa, ou na própria Itália (que detém cerca de um terço das cidades-membro), mas também existem representantes na América do Norte, Ásia, África e Oceania. Recentemente, Pijao (Quindío), uma comunidade de 6 mil habitantes da Colômbia, ganhou o título de primeira cidade lenta oficial da América Latina, enaltecendo a proteção das tradições e da arquitetura típica de uma comunidade do eixo cafeeiro local (HINCAPIÉ, 2014).

Para consolidar suas propostas e orientar o planejamento local, o Cittaslow dispõe de uma espécie de estatuto próprio, com as metas, critérios e compromissos que as cidades que desejam se tornar "lentas" devem considerar. Para se

\footnotetext{
${ }^{6}$ Além de Paolo Saturnini, por Greve in Chianti, participaram representando Orvieto, Bra e Positano, Stefano Cimicchi, Francesco Guida e Domenico Marrone, respectivamente (MAYER; KNOX, 2006). ${ }^{7}$ A ecogastronomia está atenta ao ciclo produtivo do alimento, incentivando o cultivo e o consumo de alimentos saudáveis, a cozinha típica e regional e o equilíbrio ambiental da agricultura, a partir do uso sustentável da biodiversidade (SLOW FOOD, 2013).

${ }^{8}$ International network of cities where living is good ou rete internazionale delle città del buon vivere, conforme os idiomas oficiais do movimento (inglês e italiano).
} 
candidatar, o município interessado não pode ter mais do que 50 mil habitantes, precisa pagar ao Cittaslow International uma taxa de adesão (que varia conforme o porte populacional) e precisa ser aprovado em uma análise rigorosa, atendo a uma lista de pré-requisitos. Dentre os requisitos, denominados de "requisitos para a excelência9", estão: políticas de energia e planejamento ambiental; políticas de infraestrutura; políticas de valores urbanos (que envolve a qualidade de vida e do ambiente); políticas para a agricultura, o turismo e a produção autóctone; políticas de hospitalidade, para a sensibilização e a formação da população para a filosofia Cittaslow; coesão social (para a aceitação e o envolvimento comunitário); e a participação em parecerias, para difusão e divulgação da filosofia Cittaslow (CITTASLOW, 2014).

O sucesso da proposta, no entanto, depende tanto da adesão popular, quanto do empenho do governo local. É a administração municipal que se responsabiliza por candidatar a cidade ao posto de cidade lenta, assumindo de modo formal as metas e os compromissos do movimento. Mas, como as metas envolvem aspectos ligados ao modo de vida típico local, elas só são alcançadas se a comunidade aceitar a ideia e também participar. Para Mayer e Knox (2010), é isso que faz com que a organização Cittaslow aceite apenas a candidatura de cidades pequenas e que, preferencialmente, já possuam certa vocação para a "vida lenta". Para Paolo Saturnini, por sua vez, essa preferência pode ser justificada pelo fato das cidades pequenas serem naturalmente mais propícias à "vida lenta", precisando apenas preservar (hábitos e paisagens) para manter a qualidade, enquanto que cidades grandes, por terem "mais de uma alma", precisariam revolucionar para reaver a qualidade (RUSCHEL, 2012).

Pode-se dizer, portanto, que o Cittaslow tem sua essência associada à "vida lenta", à valorização de modos de vida típicos e tradicionais, onde haja a possibilidade de se viver com qualidade e de um viver sustentável. Sua proposta une diretrizes de planejamento urbano e ambiental, com desenvolvimento econômico e preservação da identidade cultural. Suas ações visam conservar a memória e a

\footnotetext{
${ }^{9}$ A cartilha do Cittaslow (Charter), em seu "Anexo C", dispõe sobre requirements for excellence, uma lista de tópico abrangentes, onde constam ações específicas para cada tema (CITTASLOW, 2014).
} 


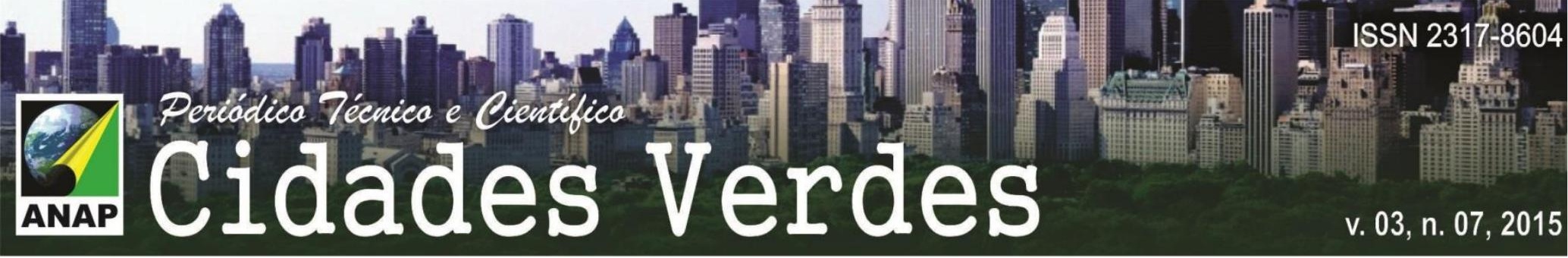

história das cidades, e também preparar cidades (e sociedades) para as demandas do futuro, promovendo a preservação da vida, a partir do desenvolvimento urbano sustentável.

\section{A VIDA LENTA E A SUSTENTABILIDADE DA CIDADE.}

A revolução do meio ambiente implica no nosso modo de pensar o mundo (SACHS, 2009, p.227).

O que correlaciona a cidade lenta com a sustentabilidade da cidade, portanto, é a vida lenta. Todas as propostas do Cittaslow (no âmbito social, cultural e ecológico) são voltadas para a proteção ou para a promoção do "modo de vida lento". Ao regular o modo de vida, o Cittaslow tenta dar equilíbrio ao desenvolvimento. Desse modo, ele estabelece um embate interessante entre a sustentabilidade do "ser" e a do "ter". Para o Cittaslow, está no "ter", isto é, no modo de vida dominado pela prática do consumo, e não no "ser", isto é, na própria existência humana, o principal aspecto que conduz nossas sociedades - e, indiretamente, nossas cidades - à insustentabilidade.

É por isso que suas ações se iniciam com a conscientização da comunidade, com a valorização do autoconhecimento e o estímulo às práticas locais. Pensa em um tipo de planejamento que se volta para a escala humana, para a aplicação de políticas e de diretrizes integradas, que possam ser traduzidas em benefícios para as pessoas (com justiça social e consciência ambiental). Dentre as estratégias que adota, em sua busca pela sustentabilidade da cidade, destacam-se as que veremos a seguir.

\subsection{Aumentar o protagonismo do campo.}

Se o alimento não for forçado a fazer jornadas intercontinentais, mas for parte de um sistema no qual ele pode ser consumido em pequenas distâncias, poderemos economizar muita energia (...). Pensem no que poderíamos economizar do ponto de vista ecológico, sem os excessos de transporte, refrigeração, embalagens que acabam no lixo, e estocagem, que rouba tempo, espaço e porções da natureza (...). Na dimensão local a 
energia e os recursos são otimizados e o desperdício é evitado (PETRINI, 2008)

A relação do homem com o campo, com as atividades produtivas, tem grande destaque na proposta do Cittaslow, pois leva "sustentabilidade" à vida econômica da comunidade. Ao aproximar o campo e a cidade, reduzindo as distâncias entre o local de produção e o local de consumo do alimento, o Cittaslow promove ganhos sociais, econômicos e ambientais. O protagonismo do campo e o estreitamento das relações locais, por exemplo, levam à valorização das pequenas indústrias, das cooperativas e das empresas locais, ou seja, dos chamados "negócios familiares", que fortalecem os vínculos da comunidade com o território e ainda alimentam a produção dos produtos típicos - pequena escala, alta qualidade. Desse modo, cria-se uma espécie de círculo virtuoso, que ajuda a impulsionar a produção local, a agricultura tradicional e faz com que os mercados locais se tornem os principais comerciantes dessa produção. O que ainda ajuda a preservar a identidade cultural, a reduzir os custos socioambientais da produção e desperta, em visitantes e residentes, o interesse de provar os produtos na mesma ambiência em que foram produzidos (MAYER; KNOX, 2010).

\title{
5.2. Contribuir para o desenvolvimento local.
}

\begin{abstract}
O desenvolvimento econômico comunitário é um movimento que tem muitas premissas para o futuro das cidades pequenas. Quando combinado com o desenvolvimento sustentável, ele busca construir "espaços econômicos alternativos" que desafiam o paradigma capitalista convencional. Espaços econômicos alternativos podem restaurar a comunidade, aumentar sua autoconfiança e fornecer serviços e produtos negligenciados pela economia principal (MAYER; KNOX, 2010, p.1559, tradução própria).
\end{abstract}

O Cittaslow é uma proposta de caráter endógeno, isto é, que se volta para o desenvolvimento local, priorizando o uso de recursos disponíveis na própria região, ou seja, típicos do lugar ou da cultura local. Para Paiva (2004), essa é uma ação que se dedica a ampliar o bem-estar de uma determinada comunidade, enfatizando as suas singularidades e a identidade cultural. O modelo endógeno, no entanto, não costuma ser restritivo, permitindo a interação do local com o global, por exemplo, ao estimular o comércio de determinados produtos (notadamente, produtos típicos). 
Em Greve in Chianti, temos um bom exemplo de como o Cittaslow aplica essa estratégia e favorece o desenvolvimento econômico local. Famosa pela produção de um vinho com estilo próprio, que leva o nome da cidade, Chianti conseguiu conciliar a preservação de sua história, sua arquitetura, suas tradições, seus ritmos de vida e até mesmo suas paisagens bucólicas (tidas como símbolos culturais da Toscana), com a produção de vinhos com renome internacional e, por consequência, comercializados em todo o mundo. Através da produção típica, portanto, Chianti tornou-se conhecida. Isso ajudou a fortalecer os laços socioeconômicos locais e a ampliar o bem-estar da comunidade, introduzindo sustentabilidade ao desenvolvimento local.

\subsection{Promover a ecologia e o planejamento ambiental.}

Algo me parece certo: o enorme potencial de que dispõe uma cidade para enriquecer seu ecossistema e não degradá-lo, como faz com tanta frequência (SACHS, 2009, p.283).

Ecologia e sustentabilidade são itens elementares na agenda do Cittaslow. A política de planejamento ambiental (energy and environmental policy, no original) é o primeiro requisito para a "excelência" da cidade lenta. Sua proposta envolve questões como: a melhoria da qualidade do ar e da água; a disponibilização de água potável para residentes; a separação e a destinação correta de dejetos e resíduos sólidos; a compostagem industrial e residencial; a purificação do esgoto coletado; a eficiência energética de prédios e sistemas públicos; a geração de energia a partir de fontes renováveis; a redução da poluição visual, sonora e luminosa das cidades, para dar mais valor às suas características históricas; maior controle do consumo de energia elétrica; e ainda outras inúmeras ações para a conservação da biodiversidade e o manejo adequado dos recursos naturais locais (CITTASLOW, 2014).

Apesar de ter caráter mais teórico do que técnico, o Cittaslow inclui em suas propostas aspectos que são encontrados em qualquer projeto de cidade "sustentável". A grande diferença é o fato do Cittaslow buscar conciliar a introdução de práticas e tecnologias ecoeficientes, com a proteção da diversidade cultural e 
ambiental de cada lugar. As casas e edifícios ecoeficientes, a redução de áreas impermeáveis dentro da malha urbana, o incentivo ao uso da bicicleta, a priorização do pedestre, favorecendo o ato de caminhar (walkability ${ }^{10}$ ), e a permacultura, entre outros, são aspectos de uma cidade sustentável que também se encontram no escopo do Cittaslow.

Seu objetivo é fazer com que as pessoas reconquistem as cidades, tirandoas das mãos das grandes empresas, de empreendedores imobiliários, das fábricas e dos carros poluentes. Para isso, o Cittaslow valoriza o patrimônio urbano e arquitetônico local, evitando a construção de novos prédios, e combate a poluição, incentivando a formação de ambientes calmos e saudáveis, a partir da multiplicação de áreas verdes e da adoção de práticas menos poluentes. A cidade do Cittaslow é, sobretudo, uma cidade compartilhada, acolhedora e cheia de lugares agradáveis, onde encontros são possíveis e comuns. Uma cidade que, sem abrir mão do seu caráter único, tenta ser sustentável através da valorização da vida (CARVALHO, 2014).

\title{
6. CONSIDERAÇÕES FINAIS: A VIDA NA VELOCIDADE ADEQUADA?
}

\begin{abstract}
Qualidade é um direito de todos (...). Vamos começar a apreciar novamente o trabalho manual e o conhecimento que isso envolve (...). Vamos novamente nos importar pelas pessoas que trabalham na terra, ter mais interesse em novas tecnologias a serviço da sustentabilidade, do ambiente e da qualidade de vida (PETRINI, 2008).
\end{abstract}

Portney (2013), em Taking Sustainable Cities Seriously, afirma que a base conceitual de uma cidade sustentável envolve, necessariamente, a sustentabilidade (urbana), o desenvolvimento econômico sustentável e a sustentabilidade comunitária (social). O Cittaslow, como visto acima, apresenta contribuições para as três áreas: promovendo ações ecoeficientes no intuito de alcançar a sustentabilidade urbana; incentivando o desenvolvimento local para garantir a sustentabilidade econômica da comunidade; e valorizando o estreitamento dos laços locais, a partir do modo de vida lento e do protagonismo comunitário, com a finalidade de proteger a unidade

\footnotetext{
${ }^{10}$ Walkability é um termo sem tradução oficial que, de modo geral, significa o quão favorável uma área é para o caminhar. É um conceito novo e importante para o planejamento urbano sustentável.
} 
social.

Para Portney (2013), a sustentabilidade só pode ser efetivamente alcançada quando as políticas públicas levam à sério a sua necessidade. Hoje, segundo o autor, grande parte das cidades, em todo o planeta, empreende alguma iniciativa no sentido de alcançar a sustentabilidade urbana, ainda que seja de caráter elitista ou pontual. O sucesso dessas iniciativas, para o autor, depende muito do grau de "seriedade" com que os governos encaram essa missão e também do porte (físico e populacional) das cidades, com chances inversamente proporcionais ao seu tamanho.

Nesse sentido, o sucesso do Cittaslow pode estar associado a dois aspectos: ao fato do Cittaslow atuar junto dos governos locais, com metas e compromissos que demandam envolvimento e participação da população; e ao fato do Cittaslow ser mais direcionado às cidades pequenas, onde o sentido de lugar e o senso de comunidade podem ser mais facilmente preservados. De todo modo, não há nada novo na filosofia Cittaslow. Muitos de seus princípios podem ser levados para toda e qualquer cidade, independente de escala, porte ou contexto. Seu maior trunfo, portanto, é a vida lenta. É através dela que o Cittaslow tenta "desacelerar para equilibrar", isto é, "desacelerar para sobreviver", e se aproxima da sustentabilidade. O equilíbrio de sua proposta está na promoção da vida na velocidade "certa". Um Cittaslow nunca é igual ao outro e o que assemelha todas as cidades lentas, dentro de uma amostragem tão heterogênea, é o apreço pelo singular, pelo local, pelos estilos de vida simples, tranquilos e lentos, que, conforme Heidegger (1988), dão sentido e significado ao "ser no mundo".

\section{REFERÊNCIAS BIBLIOGRÁFICAS}

CARVALHO, Rubens M. R. "Lentidão", território e bem-estar: o movimento da cidade lenta e a sustentabilidade do lugar. Periódico Técnico e Científico Cidades Verdes, n.02, 2014, pp. 73-89.

CITTASLOW (International). Cittaslow International Charter. 2014. Disponível em: <http://www.cittaslow.org/>. Acesso em: 30 nov. 2014.

CITTASLOW (International). Cittaslow International Network. 2015. Disponível em: <http://www.cittaslow.org/>. Acesso em: 14 abr. 2015. 
GALEANO, E. As palavras andantes. Trad. Eric Nepomuceno. 4ª ed. Porto Alegre: L\&PM, 1994.

HEIDEGGER, Martin. Ser e Tempo. Trad. Marcia S. Cavalcanti. 2a. ed. Petrópolis: Vozes, 1988.

HINCAPIÉ, Laura S. Así viven en Pijao (Quindío), el pueblo 'sin prisa' de Latinoamérica. EI

Tiempo. Bogotá, 2014. Disponível em: <http://eltiempo.com/colombia>. Acesso em: 16 abr. 2015.

KNOX, Paul L. Creating Ordinary Places: Slow Cities in a Fast World. Journal of Urban Design, Vol. 10. No. 1, p. 1-11, 2005.

KUNDERA, Milan. A Lentidão. São Paulo: Companhia das Letras, 2011.

MAYER, Heike; KNOX, Paul. Slow Cities: Sustainable Places in a Fast World. Journal of Urban Affairs, Vol. 28, No. 4, p. 321-334, 2006.

MAYER, Heike; KNOX, Paul. Small-Town Sustainability: Prospects in the Second Modernity.

European Planning Studies, Vol. 18, No. 10, p. 1545-1565, 2010.

NORBERG-SCHULZ, Christian. Gênius loci: Towards a phenomenology of architecture. Londres: Academy Editions, 1980.

PAIVA, C. A. N. Como identificar e mobilizar o potencial de desenvolvimento endógeno de uma região? In: Documentos FEE. n.59. Porto Alegre: FEE, 2004.

PETRINI, Carlo. Terra Madre: Discurso de Carlo Petrini na Cerimônia de Abertura. 2008. Disponível em: <http://terramadre.slowfoodbrasil.com/>. Acesso em: 12 jul. 2014.

PORTNEY, Kent E. Taking Sustainable Cities Seriously. Cambridge: The MIT Press, 2013.

RUSCHEL, Rogério. Cittaslow: a revolução urbana que respeita a alma. Envolverde: Jornalismo e Sustentabilidade. 2012. Disponível em: <http://envolverde.com.br>. Acesso em: 10 abr. 2014.

SACHS, I. A Terceira Margem: em busca do ecodesenvolvimento. São Paulo: Cia. das Letras, 2009.

SCHLOSSER, Eric. Fast Food Nation. New York: Penguin Books, 2001.

SLOW FOOD (Brasil). O Movimento Slow Food (Manifestos, Textos e Notícias). 2013. Disponível em: <http://www.slowfoodbrasil.com/>. Acesso em: 25 mai. 2014.

SOJA, Edward W. Geografias Pós-Modernas. Rio de Janeiro: Jorge Zahar, 1993.

TUAN, Yi-Fu. Espaço e Lugar. São Paulo: DIFEL, 1983. 